\title{
Status of Research on Stock Enhancement of Mandarin Fish in Lakes, China
}

\author{
Wei Li, Tanglin Zhang*, Zhongjie Li and Jiashou Liu \\ State Key Laboratory of Freshwater Ecology and Biotechnology, Institute of Hydrobiology, Chinese Academy of Sciences, China
}

Submission: June 01, 2018; Published: July 16, 2018

Corresponding author: Tanglin Zhang, Center of Freshwater Ecology, Institute of Hydrobiology, Chinese Academy of Sciences, Wuhan 430072, China, Email: tlzhang@ihb.ac.cn

\begin{abstract}
Mandarin fish, Siniperca chuatsi (Basilewsky), is a famous freshwater fish in China and has a relatively high market value. The fish have been stocked in lakes since the 1990s to increase populations, to pursue commercial returns and to ease conflicts between fishery development and water quality conservation. In this paper, we briefly review the status of stock enhancement of mandarin fish in China. The parameters of stock enhancement techniques including stocking size, stocking habitat, and stocking number are determined by a series of comparative experiments. Stocked mandarin fish showed good survival and growth performance, and consequently obtain better economic benefits compared with traditional fisheries of stocking. Impacts of stocked mandarin fish on wild mandarin fish populations and small-sized fish community are also dealt with. Stocking mandarin fish in lakes may have a positive role for improving water quality, suggesting that mandarin fish stocking could be a feasible bio-manipulation measure to alleviate eutrophication in Yangtze lakes.
\end{abstract}

\section{Introduction}

Mandarin fish, or Chinese perch, Siniperca chuatsi (Basilewsky), is indigenous freshwater fish to East Asia, are mostly distributed in China, Korean Peninsula, Japan, Northern Vietnam and the Amur River along the Russian borderlands [1]. It is a traditional high-valued food fish, with delicious taste, high nutritional value and little bone among muscle, and cherished by Chinese people. Therefore, mandarin fish is more widely cultured throughout the country, and is also important in stock enhanced fisheries in lakes and reservoirs due to its large size, rapid growth, short culture period, ready availability of seed, high market demand and value $[2,3]$.

Mandarin fish have unusual feeding habits. The fish only eat live fish and shrimps and do not consume dead prey or artificial diets during all life-history stages [4]. In nature it is an absolute carnivore, and was found to capture live fry of other fish species from the first feeding stages [4]. So, mandarin fish is considered to be one of the top predators in freshwater ecosystems. However, the natural resources of mandarin fish have declined sharply in the past several decades due to habitat degradation, reduced spawning grounds, overfishing and (or) eutrophication, resulting in small-sized fish species dominating fish communities in many Yangtze lakes [5]. These small-sized fish usually have low market value and potentially compete for resources with other large or medium sized commercially valuable fish. In order to utilize the abundant small-sized fish resources and to prevent small fish populations from growing excessively, stocking of piscivorous fish, especially mandarin fish, has become an important fisheries activity in lakes along the Yangtze River [6-8].

Mandarin fish have been stocked in lakes since the 1990s to increase populations, to pursue commercial returns [7], and also to ease conflicts between fishery development and water quality conservation, based on the principle of trophic cascades [9]. Mandarin fish has been stocked in many lakes totaling over 133,000 ha in the middle and low reaches of the Yangtze River [1]. It is well documented that the practice can channel more energy to large and medium sized commercially valuable fish, but also enable the recovery of the mandarin fish populations in lakes and reservoirs. Besides, our practices have indicated that stocking mandarin fish can be profitable at relatively low yields reduce the pressure of fisheries on the natural habitats [2].

\section{Stock Enhancement Techniques}

In general, stocking strategies that maximize survival of stocked individuals are necessary to fully evaluate the prospect for stock enhancement of a given species. A suite of factors, including stocking size, stocking habitat, and stocking number, have been identified as important to post-release survival and growth of stocked fish. 


\section{Stocking Size}

The choice of stocking size of mandarin fish is an important factor for the success of the practice. Stocking size is tightly related to stocking cost and its survival rate. Generally, the larger the fry or fingerlings, the higher the survival rate as well as cost. In natural water bodies, availability and palatability of prey is also vital for the survival of mandarin fish larvae, so species, density and biomass of prey should be surveyed to determine the stocking size of mandarin fish. If prey is abundant and palatable, $3 \mathrm{~cm}$ long fry were usually suggested; if not, at least $5 \mathrm{~cm}$ long fingerlings are recommended.

\section{Stocking Habitat}

The success of the first feeding of stocked mandarin fish juveniles in natural environment is vital for their survival because they feed only on live prey fish and shrimp throughout life. So, choosing appropriate stocking habitat with available prey is of real important. Previous study suggested that the stocking habitat for juvenile mandarin fish should have moderate densities of aquatic plants, because those sites have more available prey fish and provide refuge for mandarin fish, and consequently raise the survival rate of juvenile mandarin fish [10].

\section{Stocking Number}

It is generally believed that the stocking number can be determined based on prey and others predators. This is easy and an empirical approach that it is difficult to guarantee the accuracy of stocking numbers. Actually, there are many parameters that need to be addressed for determining the stocking number, including bioenergetics model of mandarin fish, ratio of production to biomass of prey fish, prey energy density, predator energy density, prey biomass, predator biomass and water temperature, utilization ratio of prey by mandarin fish, survival rate of stocked larvae, and so on. These parameters were investigated by the Group of Fisheries Ecology, Institute of Hydrobiology, Chinese Academy of Sciences since 1990s, and the estimation method of rational stocking number of mandarin fish in different water bodies was proposed [1]. For example, based on the estimation method the rational stocking number of mandarin fish juveniles with a weight of $1 \mathrm{~g}$ in Xiaosihai Lake and Biandantang Lake was 14 inds./ha and 17 inds./ha, respectively [1].

\section{Effect Evaluation}

\section{Economic benefit}

In the past decades, a major conventional fishery practice in many lakes of China has been to overfish piscivorous fish and to stock herbivorous species (e.g. grass carp) and planktivorous species (e.g. bighead carp and silver carp) $[11,12]$. Such fishery practices cause the sharp decline of the natural resources of mandarin fish and resulted in a series of ecological problems. For example, to increase bighead and silver carp production, sewage and fertilizers are used in some lakes, which accelerate eutrophication [13]. Therefore, there has been a shift in fish stocking from common carps to mandarin fish, which can be profitable at relatively low yields [2,7]. It is well documented that the practice can obtain better economic benefits $[7,14,15]$. In Niushan Lake, the yield of mandarin fish was 9.2 tons in 1995, accounting for $1.5 \%$ of the total yield, and the profit was $¥$ 368000 , which the yield of mandarin fish was 73 tons in 1999, accounting for $6.6 \%$ of the total yield, and the profit was $¥ 2920$ 000 after four consecutive years of stocking [7].

\section{Ecological effects}

Stocked mandarin fish always incorporate both fish and shrimp into their diets [8] and thus can alter the composition, densities, size distributions, and niche characteristics of wild fish populations directly or indirectly through predation or competition [16]. There is some evidence that stocked mandarin fish do not compete with wild Siniperca fishes during the critical periods of the early stocking stages [8], and mandarin fish stocking can effectively use small-sized fish and optimize and regulate the small-sized community by predation (unpublished data).

Studies on North American and European lakes have suggested that stocking piscivorous fish have direct and indirect impacts that alter the biota and water quality of lakes by topdown effects [9]. The top-down effects of piscivorous fish in lake systems predict that an increase in piscivorous fish will reduce the biomass of zooplanktivorous and benthivorous fish, leading to a reduction in phytoplankton biomass [17]. Stocking piscivorous fish in lakes has become a strategy for water quality management and a widely accepted ecological paradigm (Van Liere and Gulati, 1992). Some practices have indicated that stocking mandarin fish in lakes may have a positive role for improving water quality. It is suggested that mandarin fish stocking could be a feasible bio-manipulation measure to alleviate eutrophication for managers in shallow Yangtze lakes.

\section{Acknowledgement}

This work was financially supported by the $\mathrm{R}$ and $\mathrm{D}$ Project of Ministry of Science and Technology of China (Grant No. 2015BAD13B02). Projects of the National Natural Science Foundation of China (Grant No. 31201994 and 30830025), the Special Fund for Agro-scientific Research in the Public Interest (Grant No. 201303056).

\section{References}

1. Li W, Liu J, Zhang T, Ye S, Li Z (2014a) Handbook of stock enhancement technology for mandarin fish Siniperca chuatsi Basilewsky. Science Press, Beijing, China, pp. 1-89.

2. Liu J, Cui Y, Liu J (1998) Food consumption and growth of two piscivorous fishes, the mandarin fish and the Chinese snakehead. Journal of Fish Biology 53(5): 1071-1083.

3. Yao G, Liang X (2015) New technology of efficient ecological farming for mandarin fish. Ocean Press, Beijing, China, pp. 2-188. 
4. Chiang IK (1959) On the biology of mandarin fish, Siniperca chuatsi of Liang-Tze Lake. Acta Hydrobiologica Sinica 3: 365-385.

5. Cao W, Zhang G, Ma J, Yu D (1991) Preliminary studies on the phenomenon of size diminution of the fish resources in Lake Honghu. In: Studies on comprehensive exploitation of aquatic biological productivity and ecological environment in Lake Honghu. Honghu Research Group. China Ocean Press, Beijing, China, pp. 148-152.

6. Xie S, Cui Y, Zhang T, Fang R, Li Z (2000) The spatial pattern of the small fish community in the Biandantang Lake-a small shallow lake along the middle reach of the Yangtze River, China. Environmental Biology of Fishes 57(2): 179-190.

7. Cui Y, Li Z (2005) Fishery Resources and Conservation of Environment in Lakes of the Yangtze River Basin. Science Press, Beijing, China, pp. 335-341.

8. Li W, Hicks BJ, Guo C, Li Z, Liu J, et al. (2014b) Does hatchery-reared Siniperca chuatsi (Actinopterygii, Perciformes) compete significantly with two wild Siniperca populations for diets in a shallow lake? Hydrobiologia 741(1): 125-138.

9. Liere LV, Gulati RD (1992) Restoration and recovery of shallow eutrophic lake ecosystems in the Netherlands: epilogue. Hydrobiologia 233(1-3): 283-287.

10. Li W (2011) Ecological studies on the stocking fishery of mandarin fish Siniperca chuatsi (Basilewsky) in shallow lakes along the middle reach of the Yangtze River. Doctoral dissertation. Graduate School of Chinese Academy of Sciences, Beijing, China, pp. 93-141

11. Liu J, He B (1992) Cultivation of the Chinese freshwater fishes. Science Press, Beijing, China, p. 3.

12. Li W, Zhang T, Li Z (2010) Spatial distribution and abundance of small fishes in Xiaosihai Lake, a shallow lake along the Changjiang (Yangtze) River, China. Chinese Journal of Oceanology and Limnology 28(3): 470477.

13. Chen H (1989) Impact of aquaculture on the ecosystem of the Donghu Lake, Wuhan. Acta Hydrobiologica Sinica 13: 359-368.

14. He Y, Yu Y, Lu Y, Huang S, Qiu J (1994) Study of stock enhancement technology of mandarin fish in Zhangdu Lake. Reservoir Fisheries 3: 24-27.

15. Zhang P, Hu, W, Zhou Y (2000) Aquaculture experiment of mandarin fish in Dong Lake. Freshwater Fisheries 30(3): 40-43.

16. Skov C, Perrow MR, Berg S, Skovgaard H (2002) Changes in the fish community and water quality during seven years of stocking piscivorous fish in a shallow lake. Freshwater Biology 47(12): 23882400 .

17. Carpenter SR, Kitchell JF (1993) The Trophic Cascade in Lakes. Cambridge University press, Cambridge, UK, England.

\section{Your next submission with Juniper Publishers will reach you the below assets}

- Quality Editorial service

- Swift Peer Review

- Reprints availability

- E-prints Service

- Manuscript Podcast for convenient understanding

- Global attainment for your research

- Manuscript accessibility in different formats

( Pdf, E-pub, Full Text, Audio)

- Unceasing customer service

Track the below URL for one-step submission https://juniperpublishers.com/online-submission.php 